\title{
Research Progress of Advanced Oxidation Technology for Drinking Water Treatment
}

\author{
lixi LIU ${ }^{1}$, zhili CHEN ${ }^{*}$ \\ ${ }^{1}$ Guilin University of Technology, Environmental Science and Engineering, 541006, Guilin, Guangxi
}

\begin{abstract}
Advanced oxidation technology is attracting attention as an effective method of water treatment that can degrade various organic pollutants. The combination of photocatalysis (UV) and ozone $\left(\mathrm{O}_{3}\right)$ and titanium dioxide $\left(\mathrm{TiO}_{2}\right)$ is a promising advanced oxidation technology. The combination of ozone, hydrogen peroxide, ultraviolet light and other oxidants for catalytic oxidation is also the current mainstream advanced oxidation technology. They can effectively degrade emerging water pollutants and alleviate water pollution problems. Titanium dioxide, hydrogen peroxide, and ozone are all popular catalysts because of their low cost, non-toxicity, strong oxidizing ability, and easy contact with various surfaces.
\end{abstract}

\section{Introduction}

At present, my country's water supply treatment process cannot effectively remove refractory organics in drinking water. Process technologies such as chlorine disinfection and ozonation usually produce some disinfection byproducts such as organic halides and bromates, which are likely to cause secondary pollution problems. Ultraviolet disinfection has very low efficiency in removing organic pollutants. Emerging advanced oxidation technology can effectively deal with the difficult-to-degrade toxic organic pollutants treatment problem, and can bridge the gap between the maximum treatability achieved by traditional treatment processes and the increasingly stringent standard limits of environmental laws and regulations. High attention from environmental engineering scholars.

Advanced oxidation technology (AOTs) is a new technology developed on the basis of traditional chemical water treatment principles. Advanced oxidation processes (AOPs) are derived from advanced oxidation technologies (AOTs). Glaze proposed the generally accepted definition of advanced oxidation in 1987 and it was first applied to the degradation of organic pollutants in groundwater. After that, AOPs have been extensively studied in the field of water treatment. At present, most of the high-level oxidation processes successfully applied in water treatment are to use extremely oxidizing free radicals $\left(\mathrm{OH} \cdot, \mathrm{SO}_{4}^{-} \cdot\right.$, etc. $)$ to finally mineralize organic pollutants with strong toxic and stable chemical properties in the water. It is $\mathrm{CO}_{2}, \mathrm{H}_{2} \mathrm{O}$ and other inorganic small molecular substances, or converts pollutants into low-toxic, easily biodegradable small molecular organic substances. And its reaction with organics has very low selectivity, and the overall rate constant is mostly $10^{8} \sim 10^{10} \mathrm{M}^{-1} \cdot \mathrm{S}^{-1}$. Throughout the oxidation process, the advantages of AOPs, such as high efficiency, universal applicability and low secondary pollution, have gradually attracted people's attention, and they hope to carry out more efficient and thorough oxidation.

\section{Definition, classification and hazards of emerging pollutants}

International organizations are dedicated to defining and characterizing emerging pollutants. "Emerging" refers to new pollutants found in aquatic media and organisms, or new characteristics and effects of compounds that already exist in the environment. Norman Network defined emerging pollutants as harmful substances detected in the environment in 2016. Currently, more than 1,000 substances can be detected, mainly in 16 categories: algal toxins, defoaming agents, complexing agents, antioxidants, detergents, disinfection by-products, plasticizers, flame retardants, fragrances, gasoline additives, nanoparticles, perfluoroalkylates substances, personal care products, pharmaceuticals, pesticides, preservatives.

For all emerging pollutants, their impact on the environment and human health risks have not been fully studied, but this issue has received extensive attention from various fields. Compounds that can be produced by the conversion of emerging pollutants through drinking water treatment processes may have higher toxicity, persistence and lower biodegradability than before. The most important environmental and human impacts of emerging pollutants are: bioaccumulation, persistence, toxicity, endocrine disorders, carcinogenicity, mutagenicity and teratogenicity. Some emerging pollutants may be harmful to humans and aquatic organisms, and have endocrine disrupting effects, leading to estrogen or hormone destruction, fetal malformations and even DNA damage.

\footnotetext{
*Corresponding author: zhilichen518@foxmail.com
} 


\section{Ultraviolet combined photochemical advanced oxidation technology}

The photochemical advanced oxidation technology based on UV combined use includes photo-excited oxidation technology and photocatalytic oxidation technology. Among them, light-excited oxidation technology mainly uses $\mathrm{H}_{2} \mathrm{O}_{2}$, Fenton, sulfate (SP), $\mathrm{O}_{3}, \mathrm{HCLO}$, etc. as oxidants, and generates strong oxidizing free radicals such as $\mathrm{OH} \cdot$ and $\mathrm{SO}_{4}{ }^{-} \cdot$ under the action of $\mathrm{UV}$ radiation, and then Attack the refractory organic pollutants in the water, and finally mineralize them into small-molecule inorganic substances $\left(\mathrm{CO}_{2}, \mathrm{H}_{2} \mathrm{O}\right.$, etc. $)$.

Photocatalytic oxidation technology uses semiconductors in water as photocatalysts. When irradiated with UV energy equal to or greater than the band gap of the semiconductor catalyst, the semiconductor absorbs photons and causes photon transitions, thereby generating oxidizing holes $\left(\mathrm{h}^{+}\right)$It is paired with reducing photogenerated electrons $\left(\mathrm{e}^{-}\right)$to oxidize or reduce the water molecules, oxygen and other substances adsorbed on the surface of the semiconductor, and produce strong oxidizing $\mathrm{OH} \cdot$, and finally realize the degradation and mineralization of organic matter.

\section{1 $\mathrm{UV} / \mathrm{H}_{2} \mathrm{O}_{2}$}

In the advanced oxidation process that combines UV and $\mathrm{H}_{2} \mathrm{O}_{2}$, UV can directly photodegrade organic matter, and at the same time, the large amount of $\mathrm{OH} \cdot$ produced by UV irradiation of $\mathrm{H}_{2} \mathrm{O}_{2}$ can efficiently oxidize difficult-tobiodegradable organic matter, so that the treatment of pollutants achieves an ideal effect. The $\mathrm{UV} / \mathrm{H}_{2} \mathrm{O}_{2}$ process has become a classic oxidation process in the field of water treatment due to its high degradation and mineralization rate, simple operation, and low secondary pollution. It has a high removal ability for a wide range of organic pollutants. TAK ${ }^{[1]}$ took anabaena toxin a as the target pollutant, and explored the degradation of anabaena toxin a by the $\mathrm{UV} / \mathrm{H}_{2} \mathrm{O}_{2}$ process under UV-A and UV-C UV wavelengths. The results showed that when $\mathrm{pH}=6.7$, when the UV irradiance is $3.5 \mathrm{~mW} / \mathrm{cm}^{2}$ and the $\mathrm{H}_{2} \mathrm{O}_{2}$ dose is $0.01 \mathrm{mmol} / \mathrm{L}$, the removal rate of anabaena toxin a can reach $99 \%$ when the $\mathrm{UV}-\mathrm{C} / \mathrm{H}_{2} \mathrm{O}_{2}$ reaction reaches 30 minutes. Chuang ${ }^{[2]}$ compared the degradation of 26 kinds of low molecular weight halogenated disinfection byproducts (DBPs) by UV direct photolysis and $\mathrm{UV} / \mathrm{H}_{2} \mathrm{O}_{2}$ process respectively. The data shows that $\mathrm{UV} / \mathrm{H}_{2} \mathrm{O}_{2}$ process can quickly decompose through electron transfer, addition, and hydrogen abstraction. Halogenated disinfection by-products, thereby greatly reducing the potential toxicity of DBPs in water treatment. It can be seen that the $\mathrm{UV} / \mathrm{H}_{2} \mathrm{O}_{2}$ process is an efficient treatment method for the treatment of toxic and emerging micropolluting organic matter in the water supply.

The research on the combined $\mathrm{UV} / \mathrm{H}_{2} \mathrm{O}_{2}$ process has been relatively mature. At present, the process has achieved pilot scale applications. For example, PWN Technology Company in the Netherlands has achieved good treatment effects on the pesticides detected in drinking water such as polyacetaldehyde, clopyralic acid, and propionic acid. (After treatment, the single mass concentration is close to the EU legislative allowable limit of $0.1 \mu \mathrm{g} / \mathrm{L}$ ). On the basis of the $\mathrm{UV} / \mathrm{H}_{2} \mathrm{O}_{2}$ process, a variety of degradation prediction models and economic evaluation methods have been developed and applied, such as the group contribution method (GCM), the unit electric energy method (EE/O), etc., to optimize the UV dose and $\mathrm{H}_{2} \mathrm{O}_{2}$ dosage. Dosage and other operating parameters to achieve the maximum economy and effectiveness of the actual application of the $\mathrm{UV} / \mathrm{H}_{2} \mathrm{O}_{2}$ process. The above research shows that the $\mathrm{UV} / \mathrm{H}_{2} \mathrm{O}_{2}$ process is feasible as a green and safe environmental water treatment technology, but the technology still faces many challenges in the practical application of degradation and removal of organic pollutants, such as $\mathrm{H}_{2} \mathrm{O}_{2}$ is easy to decompose and store Difficulty in transportation, scattering and high optical density effects caused by natural organic matter (humic acid, fulvic acid, etc.), inorganic anions $\left(\mathrm{Cl}^{-}\right)$, metal cations $\left(\mathrm{Cu}^{2+}, \mathrm{Ca}^{2+}, \mathrm{Mg}^{2+}\right.$, etc.) in the water body, alkalinity, hardness Inhibition of degradation rate. Taking appropriate technical means to solve the above-mentioned problems, so as to promote the in-depth research work of the $\mathrm{UV} / \mathrm{H}_{2} \mathrm{O}_{2}$ process in actual water samples, is the prerequisite for realizing the engineering application of this process in the water treatment industry.

\section{$3.2 \mathrm{UV} / \mathrm{TiO}_{2}$}

The $\mathrm{UV} / \mathrm{TiO}_{2}$ process is a typical representative technology of photocatalytic oxidation technology. The process relies on the aforementioned technical principles to generate hydroxyl radicals to rapidly degrade organic compounds in water, and can efficiently inactivate pathogenic microorganisms, which significantly improves the efficiency of water supply treatment. In this process, compared to UVC, UVA is widely used in $\mathrm{TiO}_{2}$ photocatalysis research due to its small light scattering effect.

AUTIN [3] explored $\mathrm{UVA} / \mathrm{TiO}_{2}$ and $\mathrm{UV} / \mathrm{H}_{2} \mathrm{O}_{2}$ processes to degrade the polyacetaldehyde in surface water and synthetic water, and found that the $\mathrm{UV} / \mathrm{TiO}_{2}$ process showed a partial mineralization effect on the polyacetaldehyde. This technology has been extensively studied in the field of drinking water treatment.

Most research experiments show that the $\mathrm{UVA} / \mathrm{TiO}_{2}$ process has a significant removal effect on emerging organic pollutants (such as antibiotics) that appear in the water source, such as the use of $\mathrm{UVA} / \mathrm{TiO}_{2}$ technology to treat sulfamethoxazole and trimethoprim in the background of pure water Pyridine, degradation data show that the chronic toxicity of the aqueous solution is significantly reduced and the residual antibacterial activity is reduced.

At present, most of the photocatalytic degradation for the treatment of refractory organics in drinking water is based on laboratory-grade water as the research background. However, when $\mathrm{Li}^{[4]}$ and others studied the effect of humic acid on the kinetics and mechanism of photocatalytic degradation of tetracycline, they found that humic acid can drastically reduce the treatment efficiency 
of tetracycline by $\mathrm{UVA} / \mathrm{TiO}_{2}$, and propose the free radical scavenging effect of natural organic substances such as humic acid. At the same time, natural organic substances can also cause the surface deactivation effect of $\mathrm{TiO}_{2}$ catalyst. It can be seen that the $\mathrm{UVA} / \mathrm{TiO}_{2}$ technology is extremely susceptible to the influence of water quality components in the treatment of organic pollutants.

In order to improve the catalytic activity and recycling capacity of $\mathrm{TiO}_{2}$ catalyst in drinking water treatment, ARLOS [5] and others used $\mathrm{H}_{2} \mathrm{O}_{2}$ to assist the thermal oxidation of porous $\mathrm{TiO}_{2}$ sheets to fix $\mathrm{TiO}_{2}$. The $\mathrm{H}_{2} \mathrm{O}_{2} / \mathrm{TiO}_{2}$ catalytic material obtained in this way is irradiated by UV at $365 \mathrm{~nm}$. The degradation effect of estrogen is very significant. Subsequently, a variety of $\mathrm{TiO}_{2}$ supported materials (such as activated carbon, graphene) appeared. The research and development of new types of catalysts such as supported and doped catalysts have increased the scope of practical research and application of $\mathrm{TiO}_{2}$ catalysts in the field of drinking water treatment to a certain extent, but at the same time it has also increased the cost of catalysts. Therefore, appropriate catalyst supports and doping are selected. Materials are of great significance to the realization of engineering applications of this technology.

The hybrid process generated by combining the $\mathrm{UV} / \mathrm{TiO}_{2}$ process with other water purification technologies has become one of the most concerned research directions in the field of environmental pollution control, such as $\mathrm{UV} / \mathrm{TiO}_{2}$-ultrafiltration membrane, $\mathrm{UV} / \mathrm{TiO}_{2}$-ultrasound, etc., showing Has a huge research potential. In addition, the heterogeneous oxidation system formed by the combination of $\mathrm{H}_{2} \mathrm{O}_{2}$, PS, PMS and other oxidants with photocatalytic systems, such as $\mathrm{UV} / \mathrm{TiO}_{2} / \mathrm{H}_{2} \mathrm{O}_{2}, \mathrm{UV} / \mathrm{TiO}_{2} / \mathrm{PS}, \mathrm{UV} / \mathrm{TiO}_{2} / \mathrm{PMS}$, etc., has shown great research potential. It is worth paying attention to in the one-step exploration work. However, most of the current $\mathrm{UV} / \mathrm{TiO}_{2}$ photocatalysis research is still on the laboratory scale, and there are relatively few researches on refractory organics in real water samples.

Table 1. Comparative analysis of $\mathrm{UV} / \mathrm{H}_{2} \mathrm{O}_{2}$ and $\mathrm{UV} / \mathrm{TiO}_{2}$ processes

\begin{tabular}{|c|c|c|c|}
\hline process & advantages & disadvantage & application \\
\hline $\mathrm{UV} / \mathrm{H}_{2} \mathrm{O}_{2}$ & $\begin{array}{c}\text { Low cost, } \\
\text { simple } \\
\text { operation }\end{array}$ & $\begin{array}{c}\text { The removal } \\
\text { efficiency is } \\
\text { not high }\end{array}$ & $\begin{array}{c}\text { Industrial } \\
\text { wastewater, }\end{array}$ \\
\hline $\mathrm{UV} / \mathrm{TiO}_{2}$ & $\begin{array}{c}\text { Low energy } \\
\text { consumption, } \\
\text { secondary } \\
\text { pollution less }\end{array}$ & $\begin{array}{c}\text { difficult to } \\
\text { recycle, } \\
\text { high cost }\end{array}$ & $\begin{array}{c}\text { Industrial } \\
\text { wastewater }\end{array}$ \\
\hline
\end{tabular}

\section{Advanced Ozone Oxidation Technology}

\section{$4.1 \mathrm{O}_{3} / \mathrm{H}_{2} \mathrm{O}_{2}$}

As a kind of strong oxidation, hydrogen peroxide is often used in wastewater treatment. In wastewater treatment, hydrogen peroxide can promote ozone decomposition to produce non-selective $\mathrm{OH} \cdot$ and then mineralize organic matter in the water. $\mathrm{O}_{3} / \mathrm{H}_{2} \mathrm{O}_{2}$ has the advantages of mild conditions and simple equipment, and can increase the biodegradability of water.

Peng ${ }^{[6]}$ used the $\mathrm{O}_{3} / \mathrm{H}_{2} \mathrm{O}_{2}$ process to degrade the pyrimidine wastewater. When $\mathrm{pH}=11$, the ozone flow rate was $4 \mathrm{~g} / \mathrm{h}$, and the reaction time was $70 \mathrm{~min}, 50 \mathrm{mmoL} / \mathrm{L}$ $\mathrm{H}_{2} \mathrm{O}_{2}$ was added. The removal rates of $\mathrm{COD}$ and pyrimidine were $74.97 \%$ and $86.46 \%$, respectively. The addition of tert-butanol proves that the reaction is an $\mathrm{OH} \cdot$ oxidation reaction, and the composite first-order kinetic model is studied by mechanics. Yu ${ }^{[7]}$ studied the degradation experiment of 2,4-dichlorophenol by $\mathrm{O}_{3} / \mathrm{H}_{2} \mathrm{O}_{2}$ process. The experiment showed that the presence of $\mathrm{H}_{2} \mathrm{O}_{2}$ greatly enhanced the degradation of 2,4-dichlorophenol by ozone. With $\mathrm{O}_{3} / \mathrm{H}_{2} \mathrm{O}_{2}$ and $\mathrm{pH}$ in a certain range, the degradation effect is gradually improved. Experimental study 2, the degradation of 4-dichlorophenol is carried out step by step and finally degraded from $\mathrm{OH}$ - into small molecular organic acids. Byung ${ }^{[8]}$ studied the degradation effects of advanced oxidation technologies $\mathrm{O}_{3} / \mathrm{H}_{2} \mathrm{O}_{2}$ and $\mathrm{UV} / \mathrm{H}_{2} \mathrm{O}_{2}$ on endotoxins. Experiments show that the $\mathrm{OH} \cdot$ produced by AOPs technology has superior degradation ability to the endotoxin in the buffer solution, and the $\mathrm{O}_{3} / \mathrm{H}_{2} \mathrm{O}_{2}$ technology is better than $\mathrm{UV} / \mathrm{H}_{2} \mathrm{O}_{2}$. Advanced oxidation technology is a gentle and effective process for degrading endotoxins to eliminate E. coli in the sample.

\section{$4.2 \mathrm{O}_{3} / \mathrm{UV}$}

$\mathrm{O}_{3} / \mathrm{UV}$ is an advanced oxidation technology that combines ozone and ultraviolet irradiation. Ozone degrades organic matter under ultraviolet light. In the reaction, it can produce $\mathrm{OH} \cdot$ with stronger oxidizing ability, which can deeply mineralize organic matter in wastewater. Therefore, $\mathrm{OH}^{\cdot}$ degradation wastewater has been used in the degradation process of a variety of organic substances. Li [9] compared the degradation of salicylic acid (SA) synthetic wastewater by $\mathrm{O}_{3}, \mathrm{UV}$, and $\mathrm{O}_{3} / \mathrm{UV}$, and discussed the influence of ozone dosage, the initial $\mathrm{pH}$ value, and the reaction time. The experimental results showed that SA degradation by different methods the efficiency is $\mathrm{O}_{3} / \mathrm{UV}>\mathrm{O}_{3}>\mathrm{UV}$. When the dosage of ozone is $7 \mathrm{mg} / \mathrm{L}$, the initial concentration of salicylic acid is $40 \mathrm{mg} / \mathrm{L}$, and the initial $\mathrm{pH}=4$, the degradation rate of $\mathrm{O}_{3} / \mathrm{UV}$ is nearly $97 \%$ when the reaction is $15 \mathrm{~min}$. And verified that the reaction mechanism is $\mathrm{OH} \cdot$. Cui ${ }^{[10]}$ studied printing and dyeing wastewater under optimal conditions. The photocatalytic COD removal rate of ozone is $9 \%$ higher than that of pure ozone, and the biodegradability of water can be improved. The best ozone release intensity is $60 \%, \mathrm{HRT}=21 \mathrm{~min}$.

Table 2. Comparative analysis of $\mathrm{O}_{3} / \mathrm{H}_{2} \mathrm{O}_{2}$ and $\mathrm{O}_{3} / \mathrm{UV}$ processes

\begin{tabular}{|c|c|c|c|}
\hline process & advantages & disadvantage & application \\
\hline $\mathrm{O}_{3} / \mathrm{H}_{2} \mathrm{O}_{2}$ & $\begin{array}{c}\text { Increase } \\
\text { biodegradability } \\
\text { oxidation of } \\
\text { halogenated } \\
\text { hydrocarbons }\end{array}$ & $\begin{array}{c}\text { refractory } \\
\text { organic } \\
\text { matter }\end{array}$ \\
\hline $\mathrm{O}_{3} / \mathrm{UV}$ & $\begin{array}{c}\text { Deep } \\
\text { mineralization } \\
\text { of organic } \\
\text { matter }\end{array}$ & $\begin{array}{c}\text { Instrument is } \\
\text { vulnerable, } \\
\text { consumes } \\
\text { energy }\end{array}$ & $\begin{array}{c}\text { Dye } \\
\text { wastewater }\end{array}$ \\
\hline
\end{tabular}




\section{Conclusion}

Compared with the conventional drinking water treatment process, the advanced oxidation technology based on the combination of $\mathrm{UV} / \mathrm{O}_{3}$ and catalyst has become a hot research topic in the field of water supply treatment at home and abroad because of its high efficiency, universality and thoroughness of oxidation. The strong oxidizing free radicals produced by this process can efficiently remove refractory organics to reduce their toxicity, can effectively deal with emerging pollutants in drinking water sources and control disinfection byproducts, and can make up for the technical defects of other conventional water supply processes. However, advanced oxidation processes also have some shortcomings, such as oxidizers, high catalyst consumption, susceptibility to water quality, high operating costs, secondary pollution, etc. These disadvantages make the practical application of these processes subject to certain restrictions. Some results of these studies are summarized as follows:

(1) Carry out special research and development for new oxidants, catalysts and catalyst carriers that are cheap, stable and efficient, to reduce the application cost of this technology and increase the possibility of its practical application.

(2) Strengthen the research on the degradation kinetics and mass transfer mechanism of organic refractory pollutants based on actual water bodies, and provide references for evaluating the effectiveness and feasibility of advanced oxidation processes based on UV combined.

(3) Design and develop a systematic photoreactor that is suitable for different water quality conditions by combining UV and $\mathrm{TiO}_{2}$ with advanced oxidation integrated process, focusing on exploring the efficiency of photoreaction instruments on the use of natural light such as sunlight, and promoting advanced UV-based combined use the oxidation technology realizes the practical engineering application.

(4) The combined use of ozone and $\mathrm{UV} / \mathrm{H}_{2} \mathrm{O}_{2}$ has a better effect on the treatment of specific organic substances. With the in-depth study of catalysts, the combined use of transition metal ions and transition metal oxides and ozone will affect some high-stability organic pollutants (insecticides), Herbicides, and nitrobenzene and titanate) and other oxidation efficiency is significantly improved. Ozone can be combined with a variety of catalysts to treat more and more complex organic pollutants.

For the removal of difficult-to-degrade and toxic organic pollutants in drinking water, the advanced oxidation process based on the combination of $\mathrm{UV} / \mathrm{O}_{3}$ and catalyst has shown a broad research and application prospect. While in-depth understanding of the mechanism of this type of advanced oxidation technology, according to the water quality characteristics of different water bodies, selecting an appropriate oxidation process and other water supply treatment processes will be the mainstream direction of development in the field of water supply treatment.

\section{Acknowledgments}

《Study on mechanism and method of space and aerial remote sensing for characteristic pollutants in low-carbon chemicals fires》(21976043)

\section{References}

1. TAK, S.Y., KIM, M.K., LEE, J.E. (2018) Kinetics and degradation mechanism of Anatoxin-a during in UV$\mathrm{C} / \mathrm{H}_{2} \mathrm{O}_{2}$ reaction. J. Chemical Engineering Journal,334:1016-1022.

2. Chuang, Y.H., Parker, K.M., Mitch, W.A. (2016) Development of predictive models for the degradation of halogenated disinfection byproducts during the UV/ $\mathrm{H}_{2} \mathrm{O}_{2}$ Advanced Oxidation Process. J. Environmental Science \& Technology,50:1120911217.

3. AUTIN, O., ROMELOT, C., RUST, L. (2013) Evaluation of a UV-light emitting diodes unit for the removal of micropollutants in water for low energy advanced oxidation processes. J. Chemosphere, 92(6):745-751.

4. Li, S., HU, J. (2016) Photolytic and photocatalytic degradation of tetracycline: Effect of humic acid on degradation kinetics and mechanisms. J. Journal of Hazardous Materials, 318:134-144.

5. ARLOS, M.J., LIANG, R., ATAT-FRAILE, M.M. (2016) Photocatalytic decomposition of selected estrogens and their estrogenic activity by UV-LED irradiated $\mathrm{TiO}_{2}$, immobilized on porous titanium sheets via thermal-chemical oxidation. J. Journal of Hazardous Materials, 318:541-550.

6. Peng, R.Y., Yang, X.J. (2011) Study on treatment of wastewater containing pyrimidine by $\mathrm{O}_{3} / \mathrm{H}_{2} \mathrm{O}_{2}$. J. Journal of Environmental Engineering,5(3):601-604.

7. Yu, Y.H., Ma, J., Hou, Y.J. (2006) Degradation of 2,4dichlorophenoxyacetic acid in water by ozone hydrogen peroxide process. J. Journal of Environmental Sciences, (6):1043-1049.

8. Byung, T.O., Young, S.S., Dega, S. (2014) Oxidative degradation of endotoxin by advanced oxidation process $\left(\mathrm{O}_{3} / \mathrm{H}_{2} \mathrm{O}_{2} \& U V / \mathrm{H}_{2} \mathrm{O}_{2}\right)$. J. Hazardous Materials,279:105-110.

9. Li, Y.B., Wang, C.P., Xu, W.J. (2014) Test of degradation of salicylic acid via $\mathrm{UV} / \mathrm{O}_{3}$ process. J. Environmental Engineering,32(2):10-14.

10. Cui, D., Pang, C.L., Kong, X.Z. (2013) Application of ozone/photocatalytic oxidation to advanced treatment of printing and dyeing wastewater. J. China Water \& Wastewater,29(23):114-116. 